\title{
COMPARISON OF DEXAMETHASONE AND MIDAZOLAM IN IMPROVING THE EFFICACY OF 0.5\% BUPIVACAINE IN ULTRASOUND GUIDED SUPRACLAVICULAR BRACHIAL PLEXUS BLOCK.
}

1. FCPS, Anaesthesia Associate Professor Anaesthesiology

Rashid Latif Medical College Lahore.

2. FCPS, Anaesthesia

Department Anaesthesia

Mayo Hospital Lahore.

3. FRCS, General Surgery

Associate Professor Surgery

Rashid Latif Medical College Lahore.

4. FCPS, Radiology

Department Radiology

Mayo Hospital Lahore.

5. FCPS, General Medicine

Assistant Professor Medicine

Rashid Latif Medical College Lahore.

Correspondence Address:

Dr. Umar lqbal

Associate Professor Anaesthesiology

Rashid Latif Medical College Lahore.

umer8808@gmail.com

Article received on:

18/07/2019

Accepted for publication:

10/10/2019

\begin{abstract}
Umar Iqbal', Muhammad Akram², Ahsan Khan ${ }^{3}$, Amna Qureshi $^{4}$, Fareeha Sheikh ${ }^{5}$
\end{abstract}
ABSTRACT... Objectives: The objective of this study was to compare the additive effect of dexamethasone versus midazolam as an adjuvant to bupivacaine for the mean duration of onset of sensory block and duration of analgesia with ultrasound guided supraclavicular block. Study Design: Randomized control trail. Setting: Research was jointly conducted at Arif Memorial Hospital affiliated with Rashid Latif Medical College and KEMU/Mayo Hospital Lahore under the auspices of Department of Anesthesiology. Period: 01/02/2017 to 30/06/2017. Material \& Methods: Involved 264 patients of either sex, aged between 20-60 years undergoing upper limb surgery under ultrasound guided supraclavicular brachial plexus block. After obtaining informed consent, patients were randomly allocated into two treatment groups. Along with $0.5 \%$ bupivacaine, patients in Group-I received dexamethasone while those in Group-II received midazolam. Outcome variables were mean time to onset of sensory block and mean duration of analgesia which were noted and compared among the groups. Results: The mean age of the patients was $38.90 \pm 11.92$ years. There were $201(76.1 \%)$ male and $63(23.9 \%)$ female patients in the study group. Majority (79.2\%) of the patients belonged to ASA Class-I followed by ASA Class-II (20.8\%). Mean time to onset of sensory block was significantly shorter with dexamethasone $(10.02 \pm 1.26$ vs. $11.07 \pm 1.38$ minutes; $p<0.001)$ as compared to midazolam and this difference was significant across all age, gender and ASA groups. Mean duration

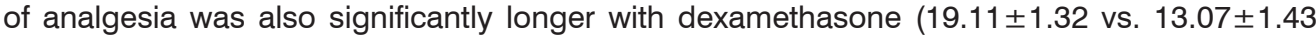
hours; $\mathrm{p}<0.001$ ) as compared to midazolam and this difference was also significant across all age, gender and ASA groups. Conclusion: Addition of dexamethasone to bupivacaine in ultrasound guided supraclavicular brachial plexus block resulted in early onset of sensory block $(10.02 \pm 1.26$ vs. $11.07 \pm 1.38$ minutes; $p<0.001)$ and longer duration of analgesia $(19.11 \pm 1.32$ vs. $13.07 \pm 1.43$ hours; $p<0.001$ ) as compared to midazolam in patients undergoing upper limb surgery irrespective of patient's age, gender and ASA status.

Key words: $\quad$ Bupivacaine, Dexamethasone, Midazolam and Bupivacaine, Supraclavicular Brachial Plexus Block, Ultrasound Guidance.

Article Citation: IqbalU,AkramM, KhanA, QureshiA, SheikhF.Comparison of dexamethasone and midazolam in improving the efficacy of $0.5 \%$ bupivacaine in ultrasound guided supraclavicular brachial plexus block. Professional Med J 2020; 27(6):1176-1181. DOI: 10.29309/TPMJ/2020.27.06.3957

\section{INTRODUCTION}

Focus of anesthesia has shifted in favor of regional blocks as compared to general anesthesia because of demerits like airway instrumentation, multidrug exposure and risks of aspiration if inadequate nil per oral status. It provides limited drug exposure, prolonged analgesia and early mobilization. ${ }^{1}$ Various techniques and methods of regional anesthesia have been employed for upper limb surgery. Intravenous regional anesthesia (Bier's Block) has been among the most favored techniques available for short duration surgery. ${ }^{2}$ For shoulder surgery, interscalene block has been practiced extensively. ${ }^{3,4}$ Ultrasound guided supraclavicular block is associated with high success rates of surgical anesthesia and low rate of complications.

In most regional anesthetic techniques bupivacaine is utilized as the drug of choice. It has the advantage of prolonged analgesia and reduced postoperative opioid requirement. ${ }^{5,6}$ Bupivacaine leads to adequate sensory and motor block in the affected limb. Many adjuncts to bupivacaine like adrenaline, magnesium sulphate, alpha-2 agonists (i.e., clonidine, 
dexmedetomidine), midazolam, 5\% dextrose and bicarbonate have been used to improve its efficacy, duration and onset of sensory blockade. ${ }^{7}$

Midazolam is known to produce antinociception and potentiate the effects of LAs by its action on ionotropic $Y$-amino butyric acid-A receptors, stimulating influx of chloride ions and resulting in inhibition of nerve impulse conduction because of membrane hyperpolarization. ${ }^{8,9}$ More recently corticosteroids have been studied as adjuncts in regional blocks. ${ }^{10}$ The addition of dexamethasone to regional anesthesia with local anesthetics has added a newer aspect to medical uses of corticosteroids. Steroids have very strong antiinflammatory and immunosuppressive effects.

Numerous randomized controlled trials and metaanalyses have examined the advantages and disadvantages of various individual adjuvants but very little comparative data is available. ElBaradey et al. studied 60 patients and found that addition of dexamethasone and midazolam provided a rapid onset of action in supraclavicular blocks $(p<0.05) .{ }^{11} \quad$ Dexamethasone alone increased rapidity of onset to $10.4 \pm 4.2 \mathrm{~min}$ as compared to $11.5 \pm 1.6 \mathrm{~min}$ in midazolam and prolonged duration of analgesia to $19.4 \pm 2$. $2 \mathrm{hrs}$ in comparison to $13.2 \pm 2.6 \mathrm{hrs}$ in midazolam. In a local study, Laiq et al. found that bupivacaine alone had onset of $22 \pm 3.5 \mathrm{~min}$ and duration of $6.20 \pm 1.8 \mathrm{hrs}$ but when used with midazolam, the onset was decreased to $14 \pm 3.1 \mathrm{~min}$ and duration increased to $9.30 \pm 4.50 \mathrm{hrs}^{12}$

This advantage of regional anesthesia and adjuvants has been validated by multiple international studies but local literature is sparse. Secondly very little data is available on the comparative effect of adding dexamethasone or midazolam to bupivacaine in local or regional population. The current study has been designed to look for unique demographic and racial features of population of Pakistan and to test the improvement in efficacy of bupivacaine when an adjuvant such as dexamethasone or midazolam is used in ultrasound guided supraclavicular brachial plexus block for upper limb surgery.

\section{MATERIAL \& METHODS}

This study is a randomized control trail, conducted at the Department of Anesthesiology Arif Memorial Hospital affiliated with Rashid Latif Medical College and KEMU/Mayo Hospital Lahore from 01/02/2017 to 30/06/2017. Approval was acquired from the ethical review board. Patients were enrolled through consecutive, non probability 1:1 sampling. Informed consent was obtained. Sample size of 264 cases (132 in each group) was calculated with $80 \%$ power of test and $95 \%$ confidence level while taking expected mean $\pm s d$ of mean duration of onset of sensory block in both groups; i-e. 10.4 \pm 4.2 minutes in dexamethasone group vs. $4.5 \pm 1.6$ minutes in midazolam group when used as adjuvant in ultrasound guided supraclavicular block. ${ }^{9}$ Patients undergoing elective surgery of the upper limb e.g. for fracture of radius, ulna and hand were enrolled. Patients of either sex, in the age range of 20-60 years were included. All of them belonged to American Society of Anesthesiology (ASA) status-I and II.

Onset was measured in minutes following administration of supraclavicular block until the loss of pin prick sensation in the anaesthetized limb and was assessed every 2 minutes. Duration of analgesia was measured in hours and it was the time from administration of anaesthetic agent to patient's first complaint of pain (VAS $>4 / 10$ ). Pain was assessed every 30 minutes using the visual analog scale (VAS) where zero (0) represents no pain and 10 meant the worst possible pain. The administration of first post-operative analgesia was at VAS $>4$

\section{DATA ANALYSIS PROCEDURE}

All the collected data was entered and analyzed through SPSS version 20. Numerical variables as age, duration of onset of sensory block and duration of analgesia have been presented by mean \pm SD. Categorical variables as gender has been presented by frequency and percentage. Independent sample t-test has been applied to compare the mean duration of onset of sensory block and mean duration of analgesia between the two groups taking $p$-value $\leq 0.05$ as significant. 


\section{RESULTS}

The age of the patients ranged from 20 years to 60 years with a mean of $38.90 \pm 11.92$ years. Majority $(n=146,55.3 \%)$ of the patients were aged between 20-40 years. There were 201 (76.1\%) male and $63(23.9 \%)$ female patients in the study group. Majority (79.2\%) of the patients belonged to ASA Class-I followed by ASA Class-II (20.8\%). There was no significant difference between the two groups in terms of mean age $(p=0.967)$, and age $(p=1.000)$, gender $(p=0.665)$ and ASA class $(p=0.880)$ groups distribution as shown in Table-l.
Mean time to onset of sensory block was significantly shorter with dexamethasone $(10.02 \pm 1.26$ vs. $11.07 \pm 1.38$ minutes; $p<0.001)$ as compared to midazolam and this difference was significant across all age, gender and ASA groups as shown in Table-II.

Mean duration of analgesia was significantly longer with dexamethasone (19.11 \pm 1.32 vs. $13.07 \pm 1.43$ hours; $p<0.001$ ) as compared to midazolam and this difference was significant across all age, gender and ASA groups as shown in Table-III.

\begin{tabular}{|c|c|c|c|c|}
\hline Characteristics & $\begin{array}{c}\text { Participants } \\
n=264\end{array}$ & $\begin{array}{c}\text { Dexamethasone }+ \\
\text { Bupivacaine } \\
n=132\end{array}$ & $\begin{array}{c}\text { Midazolam }+ \\
\text { Bupivacaine } \\
n=132\end{array}$ & P-Value \\
\hline Age (years) & $38.90 \pm 11.92$ & $38.87 \pm 11.97$ & $38.93 \pm 11.92$ & 0.967 \\
\hline \multicolumn{5}{|l|}{ Age Groups } \\
\hline $20-40$ years & 146 (55.3\%) & 73 (55.3\%) & 73 (55.3\%) & \multirow{2}{*}{1.000} \\
\hline $41-60$ years & 118 (44.7\%) & $59(44.7 \%)$ & 59 (44.7\%) & \\
\hline \multicolumn{5}{|l|}{ Gender } \\
\hline Male & 201 (76.1\%) & $102(77.3 \%)$ & 99 (75.0\%) & \multirow{2}{*}{0.665} \\
\hline Female & $63(23.9 \%)$ & $30(22.7 \%)$ & $33(25.0 \%)$ & \\
\hline \multicolumn{5}{|l|}{ ASA Class } \\
\hline Class-I & 209 (79.2\%) & 105 (79.5\%) & 104 (78.8\%) & \multirow{2}{*}{0.880} \\
\hline Class-II & 55 (20.8\%) & 27 (20.5\%) & 28 (21.2\%) & \\
\hline
\end{tabular}

\begin{tabular}{|l|l|l|l|l|}
\hline & $\begin{array}{c}\text { Participants in both } \\
\text { groups } \\
\mathbf{N}\end{array}$ & $\begin{array}{c}\text { Dexamethasone } \\
\text { Bupivacaine } \\
\mathbf{n = 1 3 2}\end{array}$ & $\begin{array}{c}\text { Midazolam }+ \\
\text { Bupivacaine } \\
\mathbf{n = 1 3 2}\end{array}$ & P-Value \\
\hline Overall & $132 / 132$ & $10.02 \pm 1.26$ & $11.07 \pm 1.38$ & $<0.001^{*}$ \\
\hline Age Groups & $73 / 73$ & $9.89 \pm 1.39$ & $10.96 \pm 1.48$ & $<0.001^{*}$ \\
\hline $20-40$ years & $59 / 59$ & $10.19 \pm 1.06$ & $11.20 \pm 1.24$ & $<0.001^{*}$ \\
\hline $41-60$ years & $102 / 99$ & $10.00 \pm 1.19$ & $10.96 \pm 1.43$ & $<0.001^{*}$ \\
\hline Gender & $30 / 33$ & $10.10 \pm 1.47$ & $11.39 \pm 1.17$ & $<0.001^{*}$ \\
\hline Male & & & & \\
\hline Female & $105 / 104$ & $10.03 \pm 1.30$ & $11.10 \pm 1.38$ & $<0.001^{*}$ \\
\hline ASA Class & $27 / 28$ & $10.00 \pm 1.07$ & $10.96 \pm 1.40$ & $0.006^{*}$ \\
\hline Class-I & Table-II. Comparison of mean time to onset of sensory block (minutes) & \\
\hline Class-II & Independent sample t-test, * observed difference was statistically significant & \\
\hline & &
\end{tabular}




\begin{tabular}{|c|c|c|c|c|}
\hline & $\begin{array}{c}\text { Participants in both } \\
\text { groups } \\
\mathbf{N}\end{array}$ & $\begin{array}{c}\text { Dexamethasone }+ \\
\text { Bupivacaine } \\
n=132\end{array}$ & $\begin{array}{c}\text { Midazolam + } \\
\text { Bupivacaine } \\
n=132\end{array}$ & P-Value \\
\hline Overall & $132 / 132$ & $19.11 \pm 1.32$ & $13.07 \pm 1.43$ & $<0.001$ * \\
\hline \multicolumn{5}{|l|}{ Age Groups } \\
\hline 20-40 years & $73 / 73$ & $19.11 \pm 1.31$ & $12.95 \pm 1.56$ & $<0.001$ * \\
\hline $41-60$ years & $59 / 59$ & $19.12 \pm 1.35$ & $13.22 \pm 1.23$ & $<0.001 *$ \\
\hline \multicolumn{5}{|l|}{ Gender } \\
\hline Male & $102 / 99$ & $19.06 \pm 1.38$ & $13.04 \pm 1.38$ & $<0.001^{*}$ \\
\hline Female & $30 / 33$ & $19.30 \pm 1.12$ & $13.15 \pm 1.56$ & $<0.001$ * \\
\hline \multicolumn{5}{|l|}{ ASA Class } \\
\hline Class-I & $105 / 104$ & $19.13 \pm 1.29$ & $13.00 \pm 1.39$ & $<0.001^{*}$ \\
\hline Class-II & $27 / 28$ & $19.04 \pm 1.48$ & $13.32 \pm 1.54$ & $<0.001$ * \\
\hline
\end{tabular}

\section{DISCUSSION}

Brachial plexus block has become a viable alternative to general anesthesia for the surgeries on the upper limb as it provides adequate muscle relaxation and an excellent intra- and postoperative analgesia. ${ }^{11}$

The advent of ultrasonography (USG) guidance for locating the brachial plexus has increased the success rate and has renewed the interest in brachial plexus block. ${ }^{11}$ It also helps to reduce the total volume of drug required to be injected for anesthetizing the plexus, thereby decreasing the chances of systemic toxicity of local anesthetics.

Majority studies available in literature have evaluated the individual effects of different additives to bupivacaine in improving its efficacy and less data is available to look for the comparative effect. This study compared the additional effect of dexamethasone versus midazolam as an adjuvant to bupivacaine for the mean duration of onset of sensory block and duration of analgesia for ultrasound guided supraclavicular block.

This study shows that the mean time to onset of sensory block was significantly shorter with dexamethasone (10.02 \pm 1.26 vs. $11.07 \pm 1.38$ minutes; $p<0.001$ ) as compared to midazolam. Our observation is in line with that of El-Baradey et al. who also observed notably less time to onset of sensory block with dexamethasone $(10.4 \pm 4.2$ vs. $11.5 \pm 1.6$ minutes; $p<0.05)$ as compared to midazolam. ${ }^{11,12}$ Alarasan et al, Meitei et al and Islam et al had similar observations for mean time to onset of sensory block on addition of dexamethasone to bupivacaine for brachial plexus block i.e., (10.36 \pm 1.99 minutes), (9.52 \pm 4.14 minutes) and (9.89 \pm 1.97 minutes) respectively. ${ }^{13-15}$ Results of several studies as Rastogi et al. in 2016 (12.19 \pm 1.45 minutes), Dalvi et al. in 2016 (12.3 \pm 1.35 minutes), Dash et al. in 2014 (12 \pm 2.9 minutes) and Nalwaya et al. in 2014 (11.6 \pm 1.39 minutes) reported similar mean time to onset of sensory block with midazolam previously. ${ }^{16-19}$

Similarly, a significant longer mean duration of analgesia was observed with dexamethasone (19.11 \pm 1.32 vs. $13.07 \pm 1.43$ hours; $p<0.001$ ) as compared to midazolam. Baradey et al. also reported comparable difference in mean duration of analgesic with dexamethasone $(19.4 \pm 2.2$ vs. $13.2 \pm 2.6$ hours; $p<0.05)$ and midazolam. ${ }^{11}$ A similar mean duration of analgesia i.e., 22.4 hours was reported previously by Dash et al in patients receiving brachial plexus block with addition of dexamethasone. ${ }^{18}$ Raghu et al. also reported the mean duration of analgesia with addition of midazolam to be $13.65 \pm 2.01$ hours, corresponding to our patients receiving midazolam. ${ }^{20}$ 
The present study is first of its kind in local population and concludes the addition of dexamethasone to bupivacaine to be superior to midazolam in terms of early onset of sensory block (10.02 \pm 1.26 vs. $11.07 \pm 1.38$ minutes; $p<0.001)$ and longer duration of pain control (19.11 \pm 1.32 vs. $13.07 \pm 1.43$ hours; $p<0.001$ ) for ultrasound guided supraclavicular brachial plexus block in patients undergoing upper limb surgery. Thus the results of the present study advocate for the future practice that dexamethasone should be used as an adjunct to bupivacaine particularly in cases where longer duration of analgesia is required.

The limitation to the study is that we did not compare the onset and duration of motor block and the side effects of dexamethasone and midazolam when used with bupivacaine which should be considered before adopting dexamethasone plus bupivacaine in routine practice. Such a study is highly recommended in future research.

\section{CONCLUSION}

Addition of dexamethasone to bupivacaine in ultrasound guided supraclavicular brachial plexus block resulted in rapid onset of sensory block and prolonged analgesia as compared to midazolam in patients undergoing upper limb surgery irrespective of patient's age, gender and ASA status.

\section{Copyright@ 10 Oct, 2019.}

\section{REFERENCES}

1. Memtsoudis SG, Thomas D, Rehana R, Jashvant P, Philip G, Ottokar S, et al. Inpatient falls after total knee arthroplasty: The role of anesthesia type and peripheral nerve blocks. Surv Anesthesiol 2014; 58:199.

2. Kazemzadeh $\mathrm{GH}$, Bameshki A, Fathi M, Jahanbakhsh $S$, Saremi E, Shoorvarzi A. Intravenous regional anesthesia (Bier Block) method for arteriovenous fistula creation in patients with end stage renal disease. J Surg Trauma 2013; 1:11-5.

3. Tandoc N, Fan L, Kolesnikov S, Kruglov A, Nader DN. Adjuvant dexamethasone with bupivacaine prolongs the duration of interscalene block: A prospective randomized trial. J Anesth 2011; 25:704-9.
4. Vieira, Peter A, Pulai, Istvan, Tsao, George C, at al. Dexamethasone with bupivacaine increases duration of analgesia in ultrasound-guided interscalene brachial plexus blockade. Euro J Anaesthesiol 2010; $27: 285-8$

5. Wu J, Buggy D, Fleischmann E, Parra-Sanches I, Treschan T, Kurz A, et al. Thoracic paravertebral regional anesthesia improves analgesia after breast cancer surgery: A randomized controlled multicentre clinical trial. Can J Anesth 2015; 62:241-51.

6. Ayling OGS, Montbriand J, Jiang J, Ladak S, Love L, Eisenberg $\mathrm{N}$, et al. Continuous regional anaesthesia provides effective pain management and reduces opioid requirement following major lower limb amputation. Euro J Vascul Endovascul Surg 2014; 48:559-64.

7. Schnabel A, Poepping DM, Kranke P, Zahn PK, PogatzkiZahn EM. Efficacy and adverse effects of ketamine as an additive for paediatric caudal anaesthesia: Aquantitative systematic review of randomized controlled trials. $\mathrm{Br} \mathrm{J}$ Anaesth 2011; 107:601-11.

8. Olkkola KT, Ahonen J. Midazolam and other benzodiazepines. Handbook Exp Pharmacol. Springer-V erlag, Berlin, Germany. 2008; (III):335-360.

9. Singh J, Verma V, Sood P, Thakur A, Rana S, Thakur $\mathrm{L}$. Midazolam as an adjunct to lignocaine at two different doses in ultrasound-guided supraclavicular brachial plexus block: A randomized controlled trial. Ain-Shams J Anaesthesiol 2016; 9(4):549-57.

10. Choi S, Rodseth R, McCartney C. Effects of dexamethasone as a local anaesthetic adjuvant for brachial plexus block: A systematic review and meta-analysis of randomized trials. $\mathrm{Br} \mathrm{J}$ Anaesth2014; 112(3):427-39.

11. El-Baradey GF, Nagat SE. The efficacy of adding dexamethasone, midazolam or epinephrine to $0.5 \%$ bupivacaine in supraclavicular brachial plexus block. Saudi J Anaesth 2014; 8(Suppl-1):78-83.

12. Laiq $N$, Khan $M N$, Arif M, Khan S. Midazolam with bupivacaine for improving analgesia quality in brachial plexus block for upper limb surgerieas. $J$ Coll Physicians Surg Pak 2008; 18:674-8.

13. Alarasan AK, Agrawal J, Choudhary B, Melhotra A, Uike $S$, Mukherji A. Effect of dexamethasone in low volume supraclavicular brachial plexus block: A doubleblinded randomized clinical study. J Anaesthesiol Clin Pharmacol 2016; 32:234-9. 
14. Meitei AJ, Debbarma MK, Singh M. Supraclavicular brachial plexus block with and without dexamethasone as an adjuvant to bupivacainelignocaine for perioperative analgesia in patients undergoing upper limb surgery: A comparative study. IOSR J Dent Med Sci 2016; 15(10):24-7.

15. Islam SM, Hossain MH, Maruf AA. Effect of addition of dexamethasone to local anaesthetics in supraclavicular brachial plexus block. JAFMC Bangladesh 2011; 7(1):11-4.

16. Rastogi B, Arora A, Gupta K, Jain M, Singh VP, Rastogi A. Effect of midazolam and $0.5 \%$ levobupivaciane combination in ultrasound-guided supraclavcular brachial plexus block for upper limb surgeries-a clinical study. J Open Anesthesiol 2016; 10(1):27-3.
17. Dalvi NP, Salunkhay H, Mohite SN. A comparative study of addition of midazolam to lignocaine-bupivacaine vs. only lignocaine-bupivacaine in brachial plexus block. Res Inno Anaesth 2016; 1(1):5-9.

18. Dash $\mathrm{S}$. Does addition of midazolam to bupivacaine prolong the analgesic characteristics of brachial plexus block? Int J Pharm Bio Sci 2014; 5(3):491-8.

19. Nalwaya D, Oza V, Batwara D, Vyas A, Parmar V. Efficacy of midazolam co-administered along with local anaesthetic solution in brachial plexus block. Int J Biomed Res 2014; 5(9):571-5.

20. Raghu R, Indira P, Kiran M, Radharama M. A comparative study of $0.375 \%$ bupivacaine with midazolam and 0.375 bupivacane for brachial plexus block in upper limb surgeries. Asain Pac J Health Sci 2015; 2:129-35.

\begin{tabular}{|c|c|c|c|}
\hline \multicolumn{4}{|c|}{ AUTHORSHIP AND CONTRIBUTION DECLARATION } \\
\hline Sr. \# & Author(s) Full Name & Contribution to the paper & Author(s) Signature \\
\hline 1 & Umar lqbal & 1st Author & \\
\hline 2 & Muhammad Akram & 2nd Author & 四. Mknes \\
\hline 3 & Ahsan Khan & 3rd Author & \\
\hline 4 & Amna Qureshi & 4th Author & विलिए \\
\hline 5 & Fareeha Sheikh & 5th Author & (x-2) \\
\hline
\end{tabular}

